Research Paper:

\title{
The Effect of Group Movie Therapy on the Activities of Daily Living Among the Older Adults
}

\author{
Narges Yaghini' ${ }^{1}$ (D) Fatemeh Sadat Izadi-Avanji ${ }^{*}$ (D), Sedigheh Miranzadeh ${ }^{1}$ (D), Hossain Akbari ${ }^{3}$ \\ 1. Department of Medical-Surgical Nursing, School of Nursing, Kashan University of Medical Sciences, Kashan, Iran. \\ 2. Trauma Nursing Research Center, School of Nursing, Kashan University of Medical Sciences, Kashan, Iran. \\ 3. Department of Biostatistics and Public Health, Faculty of Health, Kashan University of Medical Sciences, Kashan, Iran.
}

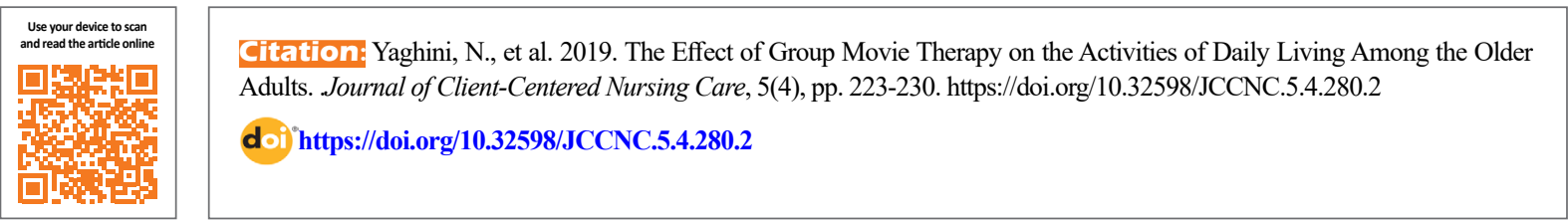

\section{(c) (1) (8)}

Article info:

Received: 15 Feb 2019

Accepted: 23 Sep 2019

Published: 01 Nov 2019

Keywords:

Basic Activities of Daily Living (BADL), Instrumental Activities of Daily Living (IADL), Group Movie Therapy (GMT), Older adult

\section{A B S T RA C T}

Background: The daily living activities are among the essential components of life and reflect an important aspect of functional independence in older adults. This study aimed to determine the effect of Group Movie Therapy (GMT) on the Activities of Daily Living (ADL) in older adults.

Methods: A randomized clinical trial was conducted on 48 older adults referred to Urban Comprehensive Health Service Centers of Kashan City, Iran. The study subjects were enrolled by a convenience sampling method and were randomly assigned to the intervention $(n=24)$ and control ( $\mathrm{n}=24)$ groups. GMT was performed in 6 weekly sessions. The Lawton's ADL Scale was used for data collection. The obtained data were analyzed by the Chi-Squared test, Fisher's Exact test, and Independent Samples t-test using SPSS.

Results: There was no significant difference in the mean scores of Basic Activities of Daily Living (BADL) and Instrumental Activities of Daily Living (IADL) before the intervention between the study groups. A significant difference was found in the mean scores of IADL after the intervention between the study groups $(\mathrm{P}=0.001)$; however, there was no significant difference in the BADL values of the groups after the intervention.

Conclusion: GMT is a non-invasive, low-cost, and non-risky way to improve the elderly's autonomy in performing IADL. Thus, GMT is recommended as a method of behavior therapy.

\section{* Corresponding Author:}

Fatemeh Sadat Izadi-Avanji, PhD.

Address: Trauma Nursing Research Center, School of Nursing, Kashan University of Medical Sciences, Kashan, Iran.

Tel: +98 (31) 55540021

E-mail:fs.izadi@gmail.com 


\section{Highlights}

- Independence in performing the basic and instrumental activities of daily living decreases health costs and increases the quality of life in the elderly.

- Activities of daily living decrease in older adults due to numerous conditions, such as declined biopsychological health, social isolation, and the medications' adverse effects.

- The current study determined the impact of Group Movie Therapy (GMT) on the activities of daily living in older adults.

- The obtained results indicated that GMT increased the instrumental activities of daily living in older adults.

- It is suggested that GMT to be used as a non-invasive, low-cost, and non-risky approach to increase the elderly's autonomy in performing the instrumental activities of daily living.

\section{Plain Language Summary}

The activities of daily living are among the essential components of life and reflect functional independence in older adults. Declined physical function could impair the activities of daily living. Geriatric nurses must be aware of the non-invasive, low-cost, and non-risky ways to increase the activities of daily living in older adults. The study findings suggested that group movie therapy could play an impotent role in improving the performance of instrumental activities of daily living, such as shopping, food preparation, housekeeping, laundry, and minor home repairs.

\section{Introduction}

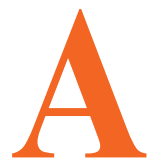

geing is associated with an increased risk of biopsychological disabilities, which sometimes threaten the independence of older adults (Vahdaninia et al. 2005). Maintenance of independence in the Activities of Daily Living (ADL) is an essential issue in geriatric nursing (Moeini et al. 2012). According to the World Health Organization (WHO), the most important component of aging health is the maintenance of the independence of the older adults in ADL until death (De Souza Vale et al. 2009). Independence is a concept beyond self-care and refers to the active participation of the elderly in their daily activities (Darvishpour et al. 2010). Daily living activities are defined as activities that a person performs typically on a daily basis to run an independent life (Van Het Bolscher-Niehuis et al. 2016).

A goal of successful aging is independence in ADL, which leads to a greater sense of life satisfaction, better personal control, and higher social interaction (Moeini et al. 2012). Therefore, it is necessary to plan appropriately to increase the independence of older adults in performing ADL (Mohammadi et al. 2018). Different techniques have been developed to maintain and enhance the independence of older adults in ADL. One of these techniques is teaching behavioral practices. Behavioral practices are being preferred to invasive methods because of their cost-effectiveness, the simplicity of performance, non-invasiveness, and the creation of a sense of independence (Newton 1995).

Group Movie Therapy GMT a behavioral practice that improves an individual's awareness, cognition, and emotion. Movies can display emotional, intellectual, and behavioral patterns for the elderly. Older adults are inspired by these patterns and use them to solve their problems (Schulenberg 2003). Movie therapy is the process of identifying and using a film, i.e., tailored to the therapeutic goals (Strong \& Lotter 2015). This modern behavioral practice is performed individually or in groups. This technique provides the context for personal and interpersonal growth (Dumtrache 2014).

Watching a movie is a multivariate experience, i.e., effective in teaching new skills and concepts, and could be used as a catalyst to evoke an emotion (Wu 2008). There are 4 stages of movie therapy, including identification, emotional evacuation, insight, and globalization. In the identification stage, the observer considers similarities between his/her world and the story characters. The evacuation phase allows individuals to bring their emotions and conflicts to the level of consciousness. In the stage of insight, the viewer interacts between one's self and 
personality. And at the last step, namely, globalization, the watcher realizes that his problems are not unique, and he could find different and effective approaches to solve them (Hosseini et al. 2016). Besides, GMT could improve adaptability and provide opportunities for sharing experiences among older adults (Yueh-ya \& Davis 2008).

The literature indicates that few studies have focused on GMT among the elderly. For example, it has been found that GMT reduces the intensity of grief (Molaie \& Abedin 2011), helps to manage stress (Abedin \& Molaie 2010), and improves depression (Lee \& Ko 2013; Kim 2014; Kwon \& Lee 2017). However, GMT was ineffective on the quality of life older adults (Jaaniste et al. 2015; Hosseini et al. 2016). Previous studies demonstrated that GMT differently influences various variables. Exploring the effect of GMT on the level of performing ADL is overlooked in the older adults. Therefore, the present study aimed to investigate the effect of GMT on ADL among the older adults. We investigated the effect of GMT on the levels of Basic Activities of Daily Living (BADL) and Instrumental Activities of Daily Living (IADL).

\section{Materials and Methods}

The present clinical trial was conducted in the older adults referred to Urban Comprehensive Health Service Centers (Akramian) of Kashan City, Iran, from July 2018 to April 2019.

No study was found on the effects of GMT on the independence of daily living activities in older adults. However, according to a survey, the mean increased score of self-esteem after receiving movie therapy was 0.78 and 8.73 in the control and intervention groups, respectively (Navidian, Saadat \& Bahari 2015). Considering total variance equal to 34.6 , type I error of $5 \%$, and a power of $95 \%$, the maximum value of between-group difference equal to 6 , and sample attrition rate of $20 \%$, the sample size was calculated as 25 subjects per group. The study sample size was computed by the following Formula 1:

$$
\text { 1. } n=\frac{\left(Z_{1-a / 2}+Z_{1-\beta}\right)^{2} \sigma^{2}}{\varepsilon^{2}}
$$

The study participants were selected using a convenience sampling technique and were assessed for eligibility to participate in the study $(\mathrm{N}=50)$. Two subjects did not meet the inclusion criteria.

The study participants were assigned to the control $(n=24)$ and intervention $(n=24)$ groups by a randomized block design using an online software application (Sealed Envelope Software, London, UK). Sealed En- velope software created a block size of 4 lists and a sequence of letters; A and B. Each letter was randomly assigned to the intervention and control groups.

Inclusion criteria were gaining scores $>20$ on the MiniMental State Examination (MMSE), age of $\geq 60$ years, being able to see the TV screen with or without glasses, being able to hear a conversation with or without hearing aids, and having no acute diseases. The exclusion criteria were missing $>1$ session of the GMT, patient's death, cognitive impairment, serious illness during the study, and unwillingness to continue participating in the study.

In the first session, the study participants were informed about the purpose and methods of the research. They were ensured of the confidentiality of their data and their right to withdraw from the study without any penalty. The study participants signed informed consent regarding participation in the study. Additionally, Lawton's Activities of Daily Living (ADL) scale and biographical information sheet were completed by the study subjects as the Pre-test. In the second session, the intervention group subjects were divided into two subgroups. GMT sessions were conducted for each subgroup. Each session averagely lasted 90 minutes, and weekly sessions were held for 6 consecutive weeks. At the end of each session, the time and place of the next meeting were reminded of the study subjects.

At each session, a part of the selected film was shown for 30 minutes. All the movies were in the Persian language. The contents provided per session are presented in Table 1. The movies were screened in a room at the Urban Comprehensive Health Service Center (Akramian).

After the end of the playback of each movie, the study participants discussed the film's characters, their personal experiences, and their feelings about it. The first author led group discussions and provided an opportunity for all the study participants to express their feelings. After the end of GMT sessions, both study groups completed the Lawton's ADL scale, as the Post-test. After the research completion, the selected films were provided to the controls, and the results of the research were presented to all of the study participants. The chart of the study process is shown in Figure 1.

The required data were collected using a two-part instrument. The first part covered a biographical information form, including age, gender, marital status, employment status, educational level, the number of children, lifestyle, a history of hypertension, as well as cholesterol and glucose levels, and a history of cardiovascular disease, backache, joint pain, and asthma. 
Table 1. Details of the intervention and the content of each GMT session

\begin{tabular}{|c|c|c|}
\hline Sessions & & Content \\
\hline First & \multicolumn{2}{|c|}{$\begin{array}{l}\text { The study participants were informed about the purpose and methods of the study. They were } \\
\text { ensured of the confidentiality of their data and their right to withdraw from the study. The study } \\
\text { participants signed informed consent for participation in the research. The questionnaires were } \\
\text { completed as the Pre-test by both study groups. }\end{array}$} \\
\hline Sessions & Movie's Name & Movie's Content \\
\hline Second & $\begin{array}{l}\text { Documentary: "Nanae Has- } \\
\qquad \text { san" }\end{array}$ & $\begin{array}{l}\text { A 76-year-old woman paints without training. In a short time, } \\
\text { she succeeds in creating beautiful paintings that reflect her past } \\
\text { life. These paintings include memories, Iranian customs, and } \\
\text { traditions. }\end{array}$ \\
\hline Third & $\begin{array}{l}\text { Documentary: “Hajeej: Dream } \\
\text { of Uraman Stone" }\end{array}$ & $\begin{array}{l}\text { The film is about the lives of two elderly couples in the village of } \\
\text { "Hajeej" in the Oraman area of Kermanshah City, Iran, who are } \\
\text { also active in old age. }\end{array}$ \\
\hline Fourth & "If not an older adult" & $\begin{array}{c}\text { This film shows a picture of the village of the elderly residents } \\
\text { who, despite being old, have the active force to set up village } \\
\text { aqueducts. }\end{array}$ \\
\hline Fifth & Film: "Tales of Majid" & $\begin{array}{l}\text { The film is about the life of an older woman and a teenage boy } \\
\text { (her grandchild) living together and experiencing problems. }\end{array}$ \\
\hline Sixth & "Life again" & $\begin{array}{l}\text { The story of a middle-aged couple who want to go to a nursing } \\
\text { home but are forced to continue living together. }\end{array}$ \\
\hline Seventh & Film: "Tales of Majid" & $\begin{array}{l}\text { The film is about the life of an older woman and a teenage boy } \\
\text { (her grandchild) living together and experiencing problems. }\end{array}$ \\
\hline Eighth & The questionnaires were & ompleted after the end of the intervention by both groups. \\
\hline
\end{tabular}

Client- Centered Nursing Care

Lawton's ADL scale was used as the second part of the study instrument. This inventory was designed by Lawton and Brody (1969) to measure the older adults' independence in the activities of daily living (Lawton and Brody 1969). The scale has two parts. The first part contains 7 items related to the BADLs, and the second part contains 9 items related to the IADLs. Each item is scored based on a 3-point Likert-type scale (no help=2; with a little help=1; unable to do $s=0$ ). The scoring range of the BADLs subscale is between 0 and 14 , and the IADLs subscale scoring has a range of 0 to 18. Higher scores in each subscale indicate the higher independence of the older adults in performing BADLs and IADLs. Lawton's ADLs scale has been translated to Persian, and its psychometric properties have been supported, and the reliability of the scale was determined using the test-retest method ( $\mathrm{r}=0.90)$. (Hekmatpou et al. 2010). In the present study, the Cronbach's alpha $(\alpha)$ coefficient of it was calculated as 0.89 .

The obtained data were analyzed using SPSS. The normality of the dependent variables was verified by the Kolmogorov-Smirnov test. Descriptive statistics, including mean and standard deviation for quantitative variables and frequency distribution for qualitative variables, were calculated. Chi-Squared test and Fisher's Exact test were used to compare the qualitative variables. The Paired Samples t-test and the Independent Samples t-test were implemented for within- and between-group comparisons. The significance level was considered to be $\mathrm{P}<0.05$.

\section{Results}

The collected data suggested no significant differences between the two groups in terms of age, gender, marital status, employment status, educational level, and lifestyle. The study participants' clinical characteristics revealed no significant difference between the study groups (Table 2).

There was no significant difference between the groups in terms of the mean pre-test, post-test scores of BADL ( $P>0.05$ ). Comparing within-group mean scores of basic $\mathrm{ADL}$ also reflected no significant difference between the two groups $(\mathrm{P}>0.05)$ (Table 3$)$.

The mean score of IADL was not significantly different before the intervention in the two groups $(\mathrm{P}>0.05)$; however, the mean score of IADL significantly differed at the Post-test between the study groups $(\mathrm{P}=0.001)$. 
Table 2. The frequency distribution of demographic and clinical characteristics of the studied groups $(\mathrm{n}=24)$

\begin{tabular}{|c|c|c|c|c|}
\hline \multirow[b]{2}{*}{ Variables } & \multirow{2}{*}{ Groups } & \multicolumn{2}{|c|}{ No. (\%) } & \multirow{2}{*}{$\mathbf{P}$} \\
\hline & & Control & Intervention & \\
\hline \multirow{2}{*}{ Gender } & Male & $10(41.7)$ & $11(45.8)$ & \multirow{2}{*}{$0.77+$} \\
\hline & Female & $14(58.3)$ & $13(54.2)$ & \\
\hline \multirow{2}{*}{ Marital status } & Married & $22(91.7)$ & $21(87.5)$ & \multirow{2}{*}{$0.63+$} \\
\hline & Single & $2(8.3)$ & $3(12.5)$ & \\
\hline \multirow{3}{*}{ Employment status } & Employed & $2(8.3)$ & $3(12.5)$ & \multirow{3}{*}{$0.67+t$} \\
\hline & Retired & $7(29.2)$ & $9(37.5)$ & \\
\hline & Housewife & $15(62.5)$ & $12(50)$ & \\
\hline \multirow{2}{*}{ Educational level } & Below diploma & $21(87.5)$ & $19(79.2)$ & \multirow{2}{*}{$0.35+$} \\
\hline & Above diploma higher & $3(12.5)$ & $5(20.8)$ & \\
\hline \multirow{2}{*}{ Lifestyle } & With family & $21(87.5)$ & $23(95.8)$ & \multirow{2}{*}{$0.14+$} \\
\hline & Single & $3(12.5)$ & $1(4.2)$ & \\
\hline \multicolumn{2}{|c|}{ Hypertension (yes) } & $7(29.2)$ & $11(45.8)$ & $0.37+$ \\
\hline \multicolumn{2}{|c|}{ High glucose level (yes) } & $5(20.8)$ & $5(20.8)$ & N.St \\
\hline \multicolumn{2}{|c|}{ High cholesterol level (yes) } & $4(16.8)$ & $6(25.2)$ & $0.72+$ \\
\hline \multicolumn{2}{|c|}{ Cardiovascular disease (yes) } & $3(12.5)$ & $6(25.2)$ & $0.46+$ \\
\hline \multicolumn{2}{|c|}{ Back ache (yes) } & $3(12.5)$ & $4(16.8)$ & $0.35+$ \\
\hline \multicolumn{2}{|c|}{ Joints pain (yes) } & $5(20.8)$ & $5(20.8)$ & N.St \\
\hline \multicolumn{2}{|c|}{ Asthma (yes) } & $1(4.2)$ & 0 & N.St \\
\hline \multicolumn{2}{|c|}{ Age $(y)( \pm S D)$} & $66.5 \pm 8.3$ & $65.9 \pm 5.2$ & $0.746+\dagger+$ \\
\hline \multicolumn{2}{|c|}{ Number of children $( \pm S D)$} & $5 \pm 1.9$ & $3.8 \pm 1.4$ & $0.018+†+$ \\
\hline
\end{tabular}

${ }^{\dagger}$ Fisher's Exact test; ${ }^{+\dagger}$ Chi-squared test; ${ }^{+t t}$ Independent Samples t-test

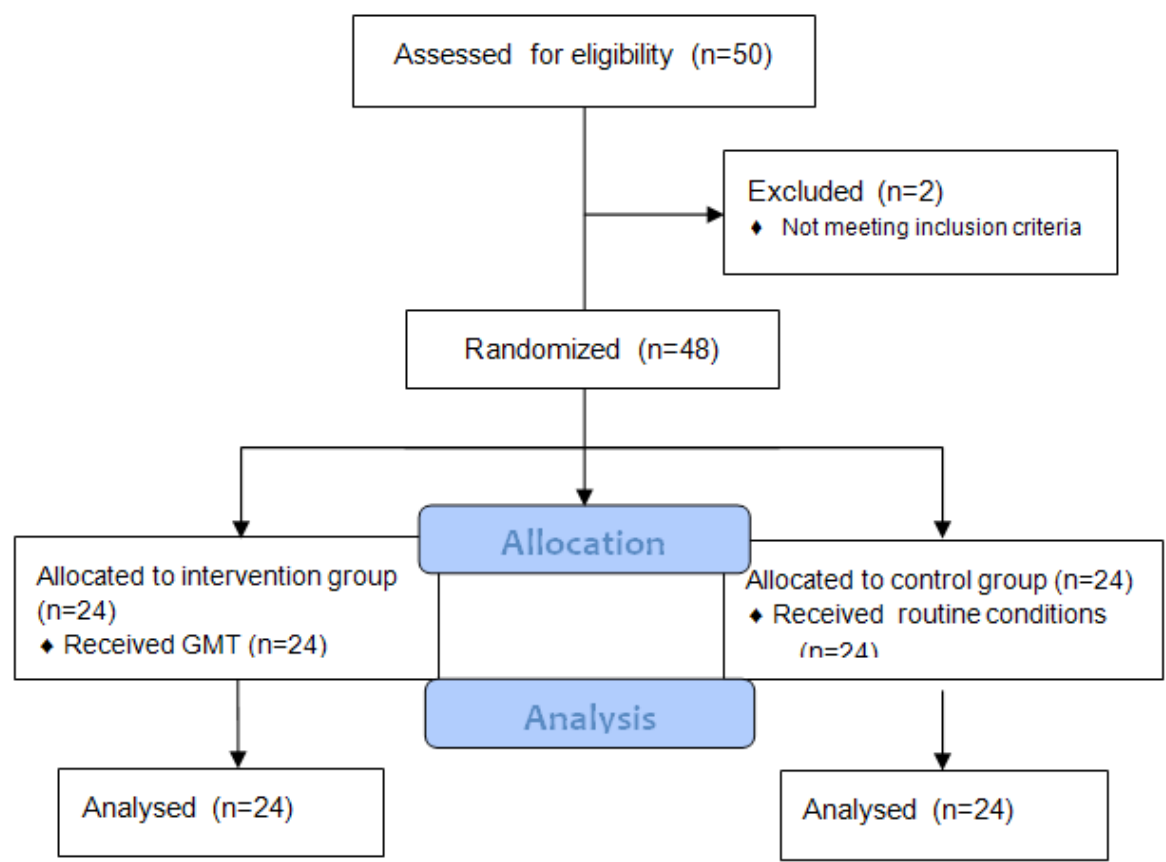

Figure 1. The chart of the process 
Table 3. Comparing the within-group and between-group mean scores of BADL and IADL $(n=24)$

\begin{tabular}{|c|c|c|c|c|}
\hline \multirow{2}{*}{ Groups } & \multirow{2}{*}{ Time } & \multicolumn{2}{|c|}{ Mean $\pm S D$} & \multirow{2}{*}{ P (Independent Samples t-test) } \\
\hline & & Control & Intervention & \\
\hline \multirow{3}{*}{ BADL } & Time $1+$ & $13.32 \pm 1.49$ & $14.24 \pm 0.25$ & 0.322 \\
\hline & Time $2+\dagger$ & $13.7 \pm 1.6$ & $14.76 \pm 4.01$ & 0.227 \\
\hline & P (Paired Samples t-test) & $\begin{array}{l}P=0.16 \\
t=-1.43\end{array}$ & $\begin{array}{l}P=0.35 \\
t=-0.94\end{array}$ & - \\
\hline \multirow{3}{*}{ IADL } & Time $1+$ & $13.6 \pm 5.4$ & $13.52 \pm 5.12$ & 0.335 \\
\hline & Time $2+\dagger$ & $13 \pm 5.4$ & $17 \pm 3.89$ & $0.001^{*}$ \\
\hline & P (Paired Samples t-test) & $\begin{array}{l}P=0.47 \\
t=-0.72\end{array}$ & $\begin{array}{c}P=0.007^{*} \\
t=2.95\end{array}$ & - \\
\hline
\end{tabular}

* The level of significance, ${ }^{\dagger}$ Before the intervention, ${ }^{+\dagger}$ After the end of the intervention

Client- Centered Nursing Care

Table 4. Comparing the Mean \pm SD of IADL subscales before and after the intervention between the study groups

\begin{tabular}{|c|c|c|c|c|c|c|}
\hline \multirow{3}{*}{ Item of IADL } & \multicolumn{2}{|c|}{ Time 1} & \multirow{3}{*}{$\mathbf{P t}$} & \multicolumn{2}{|c|}{ Time 2} & \multirow{3}{*}{ Pt } \\
\hline & \multicolumn{2}{|c|}{ Mean \pm SD } & & \multicolumn{2}{|c|}{ Mean \pm SD } & \\
\hline & Control & Intervention & & Control & Intervention & \\
\hline Ability to Use telephone & $1.8 \pm 0.5$ & $1.8 \pm 0.5$ & N.S & $1.72 \pm 0.6$ & $1.92 \pm 0.4$ & 0.17 \\
\hline Mode of transportation & $1.8 \pm 0.4$ & $1.9 \pm 0.2$ & 0.08 & $1.64 \pm 0.7$ & $1.88 \pm 0.33$ & 0.12 \\
\hline Shopping & $1.32 \pm 0.74$ & $1.36 \pm 0.56$ & 0.83 & $1.36 \pm 0.81$ & $1.8 \pm 0.4$ & $0.01^{*}$ \\
\hline Food preparation & $1.52 \pm 0.58$ & $2.28 \pm 4.1$ & 0.36 & $1.56 \pm 0.65$ & $1.9 \pm 0.2$ & $0.005^{*}$ \\
\hline Housekeeping & $1.6 \pm 0.5$ & $1.52 \pm 0.5$ & 0.57 & $1.36 \pm 0.63$ & $1.8 \pm 0.33$ & 0.06 \\
\hline Laundry & $1.44 \pm 0.58$ & $1.64 \pm 0.48$ & 0.19 & $1.36 \pm 0.63$ & $1.8 \pm 0.33$ & $0.001 *$ \\
\hline $\begin{array}{l}\text { Performing minor home repairs } \\
\text { (e.g. making electrical outlets, } \\
\text { faucets, etc.) }\end{array}$ & $1.4 \pm 3.9$ & $1 \pm 0.88$ & 0.65 & $0.56 \pm 0.76$ & $1.2 \pm 0.95$ & $0.008^{*}$ \\
\hline $\begin{array}{l}\text { Responsibility for taking medica- } \\
\text { tions }\end{array}$ & $1.88 \pm 0.43$ & $1.92 \pm 0.27$ & 0.7 & $1.84 \pm 0.55$ & $2 \pm 0.1$ & 0.15 \\
\hline Ability to manage finances & $1.3 \pm 0.8$ & $1.6 \pm 0.56$ & 0.1 & $1.28 \pm 0.84$ & $2.4 \pm 3.92$ & 0.17 \\
\hline
\end{tabular}

${ }^{\dagger}$ Independent Samples t-test; Time 1: Before the intervention; Time 2: After the end of the intervention

Within-group comparisons of the mean scores of IADLs indicated no significant difference in the control group ( $P>0.05$ ); however, the mean score of the IADL of the intervention group was statistically different at the Posttest $(\mathrm{P}=0.007)$ (Table 2).

Comparing the mean score of BADL items before and after the intervention revealed no significant differences between the two groups. However, between-group comparisons of the mean score of IADL highlighted that the mean scores of IADL subscales, including shopping ( $\mathrm{P}=0.01)$, food preparation $(\mathrm{P}=0.005)$, housekeeping $(\mathrm{P}=0.006)$, laundry $(\mathrm{P}=0.001)$, and performing minor home repairs $(\mathrm{P}=0.008)$ were significantly different before and after the intervention (Table 4).

\section{Discussion}

The present study findings suggested that GMT impacted IADL; however, it was ineffective on the BADLs of the investigated older adults. The literature review revealed that scholars have disregarded exploring the effect of GMT on the level of ADL in older adults. Studies on other variables in this regard have reported that GMT contributes to reducing the severity of sorrow (Molaie \& Abedin 2011) and stress control (Abedin \& Molaie 2010); it improves depression (Lee \& Ko 2013; Kim 2014; Kwon \& Lee 2017), and increases self-esteem (Powell et al. 2006; Navidian et al. 2015). However, some studies have indicated that GMT was ineffective on the quality of life of the elderly residing in nursing homes (Jaaniste et al. 2015; Hosseini et al. 2016). The obtained data demonstrated that GMT was 
influential on the IADL. Instrumental activities, including shopping, food preparation, laundry, and performing minor home repairs (e.g. making electrical outlets, faucets, etc.) improved in the studied elderly after receiving the GMT.

Through movie therapy, individuals learn to courageously face their limitations, remember the past and prepare themselves for the future; accordingly, one can reach beyond it, extend it, and rely on it (Van Deurzen 2012). Furthermore, GMT is a strategy to learn problem-solving skills, and individuals could experience the consequences of using it in the short-term and long-run (Strong \& Lotter 2015).

Through GMT, individuals discover and redefine their personal and inner worlds. They re-format their life pattern through finding and activating new sources of adaptation in daily living activities (Dumtrache 2014). Moreover, movies could improve adaptability among older adults and provide opportunities for group discussion and experience sharing. GMT seems to impact individuals' emotional structure. GMT increases the self-esteem and problem-solving ability of the older adults, which, in turn, enhances the IADL ability; however, it does not increase the psycho-motor dimension of the elderly for performing ADL. Therefore, GMT could be used as a non-invasive, cost-effective, and non-risky approach to enhance independence in performing $\mathrm{ADL}$ in the elderly.

Considering that the present study sample was limited to the elderly referred to the Urban Comprehensive Health Service Centers of Kashan, the generalization of the results should be considered with caution. Assessing the impact of movie therapy in combination with other therapies and studies with a long follow-up period is suggested. Besides, the participation of study subjects in all age groups of older adults could produce more beneficial outcomes.

Activities of daily life gradually declines in the older adults and GMT can be as a non-invasive, low-cost, and non-risky way to improve the elderly's autonomy in performing IADL. Thus, GMT is recommended as a method of behavior therapy to improve the quality of life of the older adults.

\section{Ethical Considerations}

\section{Compliance with ethical guidelines}

This study was approved by the Ethics Committee of Kashan University of Medical Sciences (Code: IR.KAUMS.NUHEPM.REC.1397.012) and received a code from the Iranian Registry Clinical Trial (Code: IRCT20180717040504N1). All the study participants signed the informed consent form.

\section{Funding}

The present article has been extracted from an MSc. thesis of Narges Yaghini at the Kashan University of Medical Sciences Research Department approved and funded this study (Code: 9724).

\section{Authors' contributions}

Conceptualization: Narges Yaghini, Fatemeh Sadat Izadi-Avanji, and Sedigheh Miranzadeh; Methodology and investigation: Narges Yaghini and Fatemeh Sadat Izadi-Avanji; Writing the original draft: Narges Yaghini; Writing the review and editing: Fatemeh Sadat IzadiAvanji, Sedigheh Miranzadeh; Supervision: Fatemeh Sadat Izadi-Avanji.

\section{Conflict of interest}

The authors declared no conflicts of interest.

\section{Acknowledgments}

The collaboration of older adults referred to the Urban Comprehensive Health Service Centers (Akramian) in Kashan, who participated in this research project, is appreciated. We also thank Kashan University of Medical Sciences for its financial support.

\section{References}

Abedin, A. \& Molaie, A., 2010. The effectiveness of Group Movie Therapy (GMT) on parental stress reduction in mothers of children with mild mental retardation in Tehran. Procedia, Social And Behavioral Sciences, 5, pp. 988-93. [DOI:10.1016/j. sbspro.2010.07.223]

Darvishpour, K. A., et al. 2010. [Autonomy in the elderly: A phenomenological study (Persian)]. Hakim Research Journal, 12(4), pp. 1-10. https://www.sid.ir/en/journal/ViewPaper. aspx?id=185933

De Souza Vale, R. G., et al., 2009. Effects of muscle strength and aerobic training on basal serum levels of IGF-1 and cortisol in elderly women. Archives of gerontology and geriatrics, 49(3), pp. 343-47. [DOI:10.1016/j.archger.2008.11.011] [PMID]

Dumtrache, S. D., 2014. The effects of a cinema-therapy group on diminishing anxiety in young people. Procedia-Social and Behavioral Sciences, 127, pp. 717-21. [DOI:10.1016/j.sbspro.2014.03.342]

Hekmatpou, D., et al. 2010. [The effectiveness of applying making sensitivity to re-admission caring model (Persian)]. Razi Journal of Medical Sciences, 17(75), pp. 33-50. http:/ / rjms.iums. ac.ir/article-1-1498-en.html 
Hosseini, F. A., et al. 2016. [Effectiveness of group film therapy on happiness and quality of life among elderly adults of Kahrizak nursing home (Persian)]. Journal of Health Literacy, 1(2), pp. 109-17. http://eprints.mums.ac.ir/8399/

Jaaniste, J., et al. 2015. Drama therapy with older people with dementia-does it improve quality of life? The Arts in Psychotherapy, 43, pp. 40-8. [DOI:10.1016/j.aip.2014.12.010]

Kim, H. G., 2014. Effects of a cinema therapy-based group reminiscence program on depression and ego integrity of nursing home elders. Journal of Korean Academy of Psychiatric and Mental Health Nursing, 23(4), pp. 233-41. [DOI:10.12934/jkp$\mathrm{mhn} \cdot 2014.23 .4 .233]$

Kwon, H. K. \& Lee, S. J., 2017. The effect of a movie-based nursing intervention program on rehabilitation motivation and depression in stroke patients. Journal of Korean Academy of Nursing, 47(3), pp. 345-56. [DOI:10.4040/jkan.2017.47.3.345] [PMID]

Lawton, M. P. \& Brody, E. M., 1969. Assessment of older people: Self-maintaining and instrumental activities of daily living. The Gerontologist, 9(3), pp. 179-86. [DOI:10.1093/geront/9.3 Part_1.179] [PMID]

Lee, S. E. \& Ko, S. H., 2013. The effects of cinema therapy on depression and self-esteem in people with schizophrenia. Journal of Digital Convergence, 11(10), pp. 585-92. https:// bit. ly/2zVVnD3

Moeini, B., et al. 2012. [Factors associated with the functional independence level in older adults (Persian)]. Hormozgan Medical Journal, 15(4), pp. 318-26. https://www.sid.ir/en/journal/ ViewPaper.aspx?id=255688

Mohammadi, S., et al. 2018. The relationship of basic and instrumental activities of daily living with the risk of developing pressure ulcer. Journal of Client-Centered Nursing Care, 4(2), pp. 69-79. [DOI:10.32598/jccnc.4.2.69]

Molaie, A. \& Abedin, A., 2011. Effectiveness of group movie therapy (GMT) on reduction of grief experience intensity in bereaved adolescent girls. Iranian Journal of Psychiatry and Behavioral Sciences, 5(1), pp. 25-32. [DOI:10.1016/j.sbspro.2010.07.194]

Navidian, A., Saadat, S. \& Bahari, F., 2015. [The impact of movie therapy on vulnerable women's self-esteem referring to nongovernmental social service clinics of Tehran (Persian)]. Journal of Kermanshah University of Medical Sciences, 18(10), pp. 569-78. https://sites.kowsarpub.com/jkums/articles/74005.html

Newton, A. K., 1995. Silver screens and silver linings: Using theater to explore feelings and issues. Gifted Child Today, 18(2), pp. 14-43. [DOI:10.1177/107621759501800206]

Powell, M. L., Newgent, R. A. \& Min Lee, S., 2006. Group cinematherapy: Using metaphor to enhance adolescent self-esteem. The Arts in Psychotherapy, 33(3), pp. 247-53. [DOI:10.1016/j.aip.2006.03.004]

Schulenberg, S. E., 2003. Psychotherapy and movies: On using films in clinical practice. Journal Of Contemporary Psychotherapy, 33(1), pp. 35-48. [DOI:10.1023/A:1021403726961]

Strong, P. \& Lotter, G., 2015. Reel help for real life: Film therapy and beyond. HTS Theological Studies, 71(3), pp. 1-10. [DOI:10.4102/hts.v71i3.2878]

Vahdaninia, M., et al. 2005. [Health-related quality of life in an elderly population in Iran: A population-based study (Per- sian)]. Payesh, 4(2), 113-20. https://www.sid.ir/fa/Journal/ ViewPaper.aspx?id=19894

Van Deurzen, E., 2012. Existential counselling \& psychotherapy in practice. New York: SAGE. https://books.google.com/ books?id=smkuAgAAQBAJ\&dq

Van Het Bolscher-Niehuis, M. J. T., et al. 2016. Effects of selfmanagement support programmes on activities of daily living of older adults: A systematic review. International Journal Of Nursing Studies, 61, pp. 230-47. [DOI:10.1016/j. ijnurstu.2016.06.014] [PMID]

Wu, A. Z., 2008. Applying cinema therapy with adolescents and a cinema therapy workshop [MSc. thesis]. East Bay: California State University. http://www.cinematherapy.com/pressclippings/Angela's-thesis1.pdf

Yueh-ya, E. \& Davis, D. W., 2008. Re-nationalizing China's film industry: Case study on the china film group and film marketization. Journal of Chinese Cinemas, 2(1), pp. 37-51. [DOI:10.1386/jcc.2.1.37_1] 